\title{
Pemberdayaan Bidan Dalam Pembentukan Kelas Ibu Hamil Di Unit Pelayanan Kesehatan (UPK) Abdul Radjak Pondok Gede
}

\author{
Munawaroh, Dewi Fajar Wati \\ Prodi Kebidanan Universitas MH. Thamrin \\ Email : muna.munawaroh28@gmail.com
}

\begin{abstract}
Abstrak
Pentingnya pembentukan kelas ibu hamil sesuai dengan Permenkes RI no 97 tahun 2014 pasal 46 dan 48 tentang pelayanan kesehatan masa sebelum hamil, masa hamil, persalinan dan masa sesudah melahirkan, penyelenggaraan pelayanan kontrasepsi, serta pelayanan kesehatan seksual. Unit Pelayanan Kesehatan (UPK) Abdul Radjak Pondok Gede sebagai fasilitas kesehatan tingkat pertama di wilayah Kramat Jati Jakarta Timur yang memberikan pelayanan kesehatan kepada ibu dan anak harus meningkatkan kualitas pelayanannya. Kelas ibu hamil merupakan layanan kesehatan ibu kekinian yang belum semua fasilitas kesehatan tingkat pertama memilikinya, sehingga hal ini dapat menjadi nilai jual dalam pengembangan UPK Abdul Radjak Pondok Gede. Metode pembentukan Kelas Ibu Hamil di UPK Abdul Radjak dilakukan sebanyak 4 kali pertemuan secara virtual dengan menggunakan zoom meeting. Setiap pertemuan dihadiri oleh ibu hamil, bidan UPK Abdul Radjak dan pendamping. Kegiatan yang diberikan dalam kelas ibu hamil adalah materi seputar kehamilan, bersalin, nifas dan bayi baru lahir serta aktivitas fisik. Pengetahuan peserta diukur dengan pre dan post test. Pengetahuan pada kelas ibu hamil I adalah $67 \%-78 \%$ pada pre test meningkat menjadi $87 \%-100 \%$ pada post test. Pengetahuan pada kelas ibu hamil II adalah $60 \%-80 \%$ pada pre test meningkat menjadi $90 \%-100 \%$. Pengetahuan pada kelas ibu hamil III adalah $57 \%-85 \%$ pada pre test meningkat menjadi $85 \%-100 \%$ pada post test. Dan pengetahuan pada kelas ibu hamil IV adalah $43 \%-85 \%$ pada pre test meningkat menjadi $86 \%-100 \%$ pada post test. Terdapat peningkatan pengetahuan pada kegiatan kelas ibu hamil di UPK Abdul Radjak Pondok Gede, serta telah terbentuk struktur organisasi pada Kamis, 3 November 2020.
\end{abstract}

Keyword: Kelas Ibu Hamil, Unit Pelayanan Kesehatan (UPK)

Abstract

The importance of the formation of classes for pregnant women in accordance with the Minister of Health Republic of Indonesia No. 97 of 2014 articles 46 and 48 concerning health services before pregnancy, pregnancy, childbirth and post-delivery, contraceptive services and sexual health services The Abdul Radjak Pondok Gede Health Service Unit (UPK) as the first level health facility in the Kramat Jati area of East Jakarta that provides health services to mothers and children must improve the quality of its services. Pregnant women class is a current maternal health service that not all first-level health facilities have it, so this can be a selling point in the development of UPK Abdul Radjak Pondok Gede. The method of forming a Pregnant Women Class at UPK Abdul Radjak was conducted in 4 virtual meetings using zoom meetings. Each meeting was attended by pregnant women, UPK midwife Abdul Radjak and their companions. Activities provided in the class for pregnant women are material about pregnancy, childbirth, childbirth and newborns as well as physical activities. Participants' knowledge was measured by pre and post test. Knowledge of the class of pregnant women I was $67 \%-78 \%$ in the pre test increased to $87 \%$ http://ejournal.urindo.ac.id/index.php/PAMAS

Article History : 
$100 \%$ in the post test. Knowledge of class II pregnant women is $60 \%-80 \%$ in the pre test increases to $90 \%-100 \%$. Knowledge of class III pregnant women is $57 \%-85 \%$ in the pre test increases to $85 \%$ $-100 \%$ in the post test. And knowledge in the class of IV pregnant women is $43 \%-85 \%$ in the pre test increases to $86 \%-100 \%$ in the post test. There is an increase in knowledge on pregnant women class activities at UPK Abdul Radjak Pondok Gede, and an organizational structure has been formed on Thursday, November 3, 2020.

Keyword: Pregnant Women Class, Health Service Unit (UPK

\section{PENDAHULUAN}

Upaya peningkatan kesehatan ibu dan anak, terutama pada kelompok rentan kesehatan, yaitu ibu hamil, bersalin dan bayi pada masa perinatal masih diprioritaskan pada program pembangunan di Indonesia. Hal ini di tandai dengan tingginya Angka Kematian Ibu (AKI) dan Angka Kematian Bayi (AKB).

Pada umumnya, penyuluhan kesehatan ibu dan anak masih dilakukan perorangan atau per kasus yang diberikan pada saat pemeriksaan kehamilan atau pada kegiatan posyandu. Kelas ibu hamil merupakan sarana untuk belajar bersama tentang kesehatan bagi ibu hamil, yang berupa tatap muka dalam kelompok yang bertujuan untuk meningkatkan pengetahuan dan keterampilan ibu-ibu tentang kehamilan, persalinan, KB pasca persalinan, pencegahan komplikasi, perawatan bayi baru lahir dan aktivitas fisik/senam hamil.

Pentingnya pembentukan kelas ibu hamil sesuai dengan Permenkes RI no 97 tahun 2014 pasal 46 dan 48 tentang pelayanan kesehatan masa sebelum hamil, masa hamil, persalinan dan masa sesudah melahirkan, penyelenggaraan pelayanan kontrasepsi, serta pelayanan kesehatan seksual.

Unit Pelayanan Kesehatan (UPK) Abdul Radjak Pondok Gede sebagai salah satu Fasilitas Pelayanan Kesehatan tingkat dasar yang bekerja sama dengan BPJS dan memberikan pelayanan kesehatan pada ibu hamil saat ini belum memiliki kelas ibu hamil. Dengan demikian maka pembentukan kelas ibu hamil ini sangat diharapkan oleh UPK Abdul Radjak Pondok Gede, BPJS kesehatan dan ibu hamil yang melakukan pemeriksaan kehamilannya di UPK Abdul Radjak Pondok Gede. 


\section{METODE PELAKSANAAN}

Kegiatan Pengabdian kepada masyarakat ini dilakukan guna membentuk struktur organisasi kelas ibu hamil di UPK Abdul Radjak Pondok Gede. Pembentukan struktur organisasi kelas ibu hamil dilakukan dalam beberapa tahap, yaitu (1) Melakukan Brain Storming kepada Kepala UPK, bidan penanggung jawab dan bidan pelaksana. (2) Menjelaskan program kerja kelas ibu hamil. (3) Melakukan pembentukan struktur organisasi kelas ibu hamil sampai dengan di SK kan. (4) sosialisasi kepada masyarakat setempat tentang adanya kelas ibu hamil .

\section{HASIL DAN PEMBAHASAN}

Pembentukan Kelas Ibu Hamil di UPK Abdul Radjak Pondok Gede telah dilakukan sebanyak 4 kali pertemuan secara virtual dengan menggunakan zoom meeting. Dalam setiap sesi pertemuan dihadiri oleh ibu hamil, bidan UPK Abdul Radjak Pondok Gede dan pendamping kelas ibu hamil. Adapun kegiatan yang diberikan dalam kelas ibu hamil adalah penyampaian materi seputar kehamilan, bersalin, nifas dan bayi baru lahir serta aktivitas fisik (Prenatal Gentle Yoga). Sebelum dan sesudah penyampaian materi oleh bidan, peserta kelas ibu hamil diberikan pre test dan post test untuk mengukur pengetahuan peserta. Hasil pre test dan post test pada kegiatan pembentukan kelas ibu hamil disajikan dalam tabel berikut ini.

\section{Tabel 1}

\section{Distribusi Frekuensi Hasil Pre Test dan Post Test Pelaksanaan Kelas Ibu Hamil Pertemuan I Di UPK Abdul Radjak Pondok Gede}

\begin{tabular}{|r|l|c|c|c|c|}
\hline \multicolumn{1}{|c|}{ No. } & \multicolumn{1}{|c|}{ Pertanyaan } & \multicolumn{2}{c|}{ Pre test } & \multicolumn{2}{c|}{ Post Test } \\
\cline { 3 - 5 } & & Jumlah & $\%$ & $\begin{array}{c}\text { Jumla } \\
\text { h }\end{array}$ & \% \\
\hline 1. & $\begin{array}{l}\text { Suatu keadaan dimana dalam rahim seorang wanita } \\
\text { terdapat hasil konsepsi, disebut dengan.... }\end{array}$ & 9 & 100 & 9 & 100 \\
\hline 2. & Dibawah ini adalah tanda dari kehamilan, kecuali..... & 9 & 100 & 9 & 100 \\
\hline 3. & $\begin{array}{l}\text { Pusing, mual muntah, kaki bengkak, sulit tidur dan } \\
\text { kram kaki adalah keluhan pada..... }\end{array}$ & 6 & 67 & 8 & 89 \\
\hline 4. & $\begin{array}{l}\text { Makanan pertama pada bayi baru lahir yang keluar } \\
\text { dari payudara ibu sebelum air susu ibu, disebut } \\
\text { dengan..... }\end{array}$ & 9 & 100 & 9 & 100 \\
\hline
\end{tabular}




\begin{tabular}{|c|c|c|c|c|c|}
\hline 5. & $\begin{array}{l}\text { Dibawah ini adalah contoh perubahan emosional pada } \\
\text { ibu hamil khususnya pada perubahan fungsi otak } \\
\text { adalah..... }\end{array}$ & 9 & 100 & 9 & 100 \\
\hline 6. & $\begin{array}{l}\text { Dibawah ini adalah contoh perubahan emosional pada } \\
\text { ibu hamil khususnya pada perubahan suasana hati } \\
\text { adalah.... }\end{array}$ & 9 & 100 & 9 & 100 \\
\hline 7. & $\begin{array}{l}\text { Dibawah ini adalah anjuran pemeriksaan ibu hamil } \\
\text { pada masa pandemic covid-19, kecuali.... }\end{array}$ & 6 & 67 & 9 & 100 \\
\hline 8. & $\begin{array}{l}\text { Pada pembagian usia kehamilan dibagi menjadi } \\
\text { berapa trimester .... }\end{array}$ & 9 & 100 & 9 & 100 \\
\hline 9. & $\begin{array}{l}\text { Pada ibu hamil usia kehamilan } 14-28 \text { minggu masuk } \\
\text { kedalam kategori trimester berapa..... }\end{array}$ & 9 & 100 & 9 & 100 \\
\hline 10 & $\begin{array}{l}\text { Pada ibu hamil usia kehamilan } 29-40 \text { minggu masuk } \\
\text { kedalam kategori trimester berapa..... }\end{array}$ & 7 & 78 & 9 & 100 \\
\hline 11. & $\begin{array}{l}\text { Pemeriksaan kehamilan yang sering dan lebih banyak } \\
\text { dilakukan selama pandemic covid-19 adalah pada } \\
\text { kehamilan trimester..... }\end{array}$ & 6 & 67 & 9 & 100 \\
\hline 12. & Kapan ibu hamil harus segera periksa kehamilannya..... & 6 & 67 & 8 & 89 \\
\hline 13 & $\begin{array}{l}\text { Dibawah ini adalah kejadian ibu hamil yang harus } \\
\text { segera dilakukan pemeriksaan, kecuali..... }\end{array}$ & 7 & 78 & 8 & 89 \\
\hline 14 & $\begin{array}{l}\text { Bagaimana cara menjaga ibu hamil sehat dan janin } \\
\text { sehat-cerdas.... }\end{array}$ & 9 & 100 & 9 & 100 \\
\hline 15 & $\begin{array}{l}\text { Berikut ini adalah hal-hal yang harus dihindari oleh ibu } \\
\text { selama hamil, kecuali..... }\end{array}$ & 9 & 100 & 9 & 100 \\
\hline
\end{tabular}

Berdasarkan tabel 1 didapatkan hasil bahwa:

1. Pada pre test dari 9 responden terdapat 6 responden (67\%) dapat menjawab pertanyaan no 3 dan pada post test meningkat menjadi 8 responden (89\%)

2. Pada pre test dari 9 responden terdapat 6 responden (67\%) dapat menjawab pertanyaan no. 7 dan pada post test meningkat menjadi 9 responden (100\%) 
3. Pada pre test dari 9 responden terdapat 7 responden (78\%) dapat menjawab pertanyaan no. 10 dan pada post test meningkat menjadi 9 responden (100\%)

4. Pada pre test dari 9 responden terdapat 6 responden (67\%) dapat menjawab pertanyaan no. 11 dan pada post test meningkat menjadi 9 responden (100\%)

5. Pada pre test dari 9 responden terdapat 6 responden (67\%) dapat menjawab pertanyaan no. 12 dan pada post test meningkat menjadi 8 responden (89\%)

6. Pada pre test dari 9 responden terdapat 7 responden (78\%) dapat menjawab pertanyaan no. 13 dan pada post test meningkat menjadi 8 responden (89\%)

Pada pertemuan pertama kelas ibu hamil dengan materi Pemeriksaan Kehamilan Agar Ibu dan Janin Sehat dihadiri oleh 9 peserta. Seluruh peserta ibu hamil mengisi pre test dan post test dengan google form yang terdiri dari 15 pertanyaan. Dari 15 pertanyaan tersebut 9 pertanyaan mampu dijawab dengan benar oleh seluruh peserta pada pre test dan post test. Sementara 6 pertanyaan lainnya dapat dijawab dengan benar antara 6-7 (67\%-78\%) responden pada pre test dan meningkat menjadi $87 \%-100 \%$ menjawab benar pada post test. Meskipun tidak seluruh pertanyaan dapat di jawab dengan benar oleh peserta pada post test namun secara keseluruhan dapat disimpulkan bahwa terdapat peningkatan pengetahuan peserta kelas ibu hamil pada pertemuan I.

Tabel 2

\section{Distribusi Frekuensi Hasil Pre Test dan Post Test Pelaksanaan Kelas Ibu Hamil Pertemuan II Di UPK Abdul Radjak Pondok Gede}

\begin{tabular}{|r|l|c|c|c|c|}
\hline \multicolumn{1}{|c|}{ No. } & \multicolumn{1}{|c|}{ Pertanyaan } & \multicolumn{2}{c|}{ Pre test } & \multicolumn{2}{c|}{ Post Test } \\
\cline { 3 - 5 } & & Jumlah & \% & Jumlah & $\%$ \\
\hline 1. & $\begin{array}{l}\text { Keluar lendir bercampur darah merupakan salah satu } \\
\text { tanda persalinan akan berlangsung }\end{array}$ & 10 & 100 & 10 & 100 \\
\hline 2. & $\begin{array}{l}\text { Suami dan keluarga sebaiknya memberikan dukungan } \\
\text { semangat pada saat persalinan }\end{array}$ & 10 & 100 & 10 & 100 \\
\hline 3. & Persalinan yang aman sebaiknya ditolong oleh dukun & 10 & 100 & 10 & 100 \\
\hline 4. & Kepanjangan dari IMD adalah Inisiasi Menyusu Dini & 7 & 70 & 9 & 90 \\
\hline 5. & $\begin{array}{l}\text { Ibu sebaiknya mulai menyusui bayinya menunggu setelah } \\
\text { ASI keluar }\end{array}$ & 6 & 60 & 10 & 100 \\
\hline 6. & $\begin{array}{l}\text { Waktu yang paling tepat untuk ber-KB adalah setelah } \\
\text { selesai masa nifas }\end{array}$ & 9 & 90 & 10 & 100 \\
\hline 7. & $\begin{array}{l}\text { KB pil merupakan jenis KB yang tepat digunakan setelah } \\
\text { persalinan }\end{array}$ & 6 & 60 & 9 & 90 \\
\hline
\end{tabular}




\begin{tabular}{|c|c|c|c|c|c|}
\hline 8. & $\begin{array}{l}\text { Membebat perut kencang-kencang setelah persalinan } \\
\text { dapat mempercepat pemulihan perut yang kendor }\end{array}$ & 8 & 80 & 10 & 100 \\
\hline 9. & $\begin{array}{l}\text { Istirahat yang cukup merupakan salah satu kegiatan yang } \\
\text { dapat dilakukan ibu untuk menjaga ibu bersalin, nifas dan } \\
\text { bayi sehat }\end{array}$ & 10 & 100 & 10 & 100 \\
\hline 10. & $\begin{array}{l}\text { Selama masa nifas, ibu cukup } 2 \text { kali memeriksakan diri ke } \\
\text { bidan }\end{array}$ & 7 & 70 & 10 & 100 \\
\hline
\end{tabular}

Berdasarkan tabel 2 didapatkan hasil :

1. Pada pre test dari 10 responden terdapat 7 responden $(70 \%)$ dapat menjawab pertanyaan no. 4 dan pada post test meningkat menjadi 9 responden $(90 \%)$

2. Pada pre test dari 10 responden terdapat 6 responden (60\%) dapat menjawab pertanyaan no. 5 dan pada post test meningkat menjadi 10 responden (100\%)

3. Pada pre test dari 10 responden terdapat 9 responden (90\%) dapat menjawab pertanyaan no. 6 dan pada post test meningkat menjadi 10 responden (100\%)

4. Pada pre test dari 10 responden terdapat 6 responden (60\%) dapat menjawab pertanyaan no.7 dan pada post test meningkat menjadi 9 responden (90\%)

5. Pada pre test dari 10 responden terdapat 8 responden $(80 \%)$ dapat menjawab pertanyaan no. 8 dan pada post test meningkat menjadi 10 responden (100\%)

6. Pada pre test dari 10 responden terdapat 7 responden (70\%) dapat menjawab pertanyaan no.10 dan pada post test meningkat menjadi 10 responden (100\%)

Pada pertemuan kedua kelas ibu hamil dengan materi Persalinan Aman, Nifas Nyaman, Ibu Selamat Bayi Sehat dihadiri oleh 10 peserta. Seluruh peserta ibu hamil mengisi pre test dan post test dengan menggunakan google form yang terdiri dari 10 pertanyaan. Dari 10 pertanyaan tersebut 4 pertanyaan dapat dijawab dengan benar oleh seluruh responden pada saat pre test. Sementara 6 pertanyaan lainnya 6-8 (60\%-80\%) responden dapat menjawab benar pada saat pre test dan meningkat menjadi $90 \%-100 \%$ pada saat post test. Pada pertemuan kedua kelas ibu hamil dapat disimpulkan bahwa terjadi peningkatan pengetahuan pada peserta. 


\section{Tabel 3}

Distribusi Frekuensi Hasil Pre Test dan Post Test Pelaksanaan Kelas Ibu Hamil Pertemuan III Di UPK Abdul Radjak Pondok Gede

\begin{tabular}{|c|c|c|c|c|c|}
\hline \multirow[t]{2}{*}{ No. } & \multirow[t]{2}{*}{ Pertanyaan } & \multicolumn{2}{|c|}{ Pre test } & \multicolumn{2}{|c|}{ Post Test } \\
\hline & & Jumlah & $\%$ & Jumlah & $\%$ \\
\hline 1. & $\begin{array}{l}\text { Demam, menggigil dan berkeringat merupakan gejala- } \\
\text { gejala malaria }\end{array}$ & 7 & 100 & 7 & 100 \\
\hline 2. & $\begin{array}{l}\text { Kehamilan diluar kandungan merupakan salah satu akibat } \\
\text { infeksi malaria terhadap ibu }\end{array}$ & 5 & 71 & 7 & 100 \\
\hline 3. & $\begin{array}{l}\text { Tidur di dalam kelambu merupakan salah satu cara } \\
\text { mencegah malaria }\end{array}$ & 7 & 100 & 7 & 100 \\
\hline 4. & $\begin{array}{l}\text { Setia pada pasangan merupakan salah satu cara mencegah } \\
\text { penyakit menular seksual/HIV-AIDS }\end{array}$ & 7 & 100 & 7 & 100 \\
\hline 5. & $\begin{array}{l}\text { Ibu hamil yang kurang energi kronis (KEK) dapat berakibat } \\
\text { bayi yang dilahirkan besar }\end{array}$ & 6 & 85 & 7 & 100 \\
\hline 6. & $\begin{array}{l}\text { Makan makanan yang bergizi dan bervariasi merupakan } \\
\text { salah satu cara mencegah ibu yang kurang energi kronis } \\
\text { (KEK) }\end{array}$ & 5 & 71 & 7 & 100 \\
\hline 7. & $\begin{array}{l}\text { Anemia pada saat kehamilan dapat meningkatkan risiko } \\
\text { perdarahan pada saat persalinan }\end{array}$ & 4 & 57 & 6 & 85 \\
\hline 8. & $\begin{array}{l}\text { Perdarahan merupakan salah satu tanda bahaya } \\
\text { kehamilan }\end{array}$ & 7 & 100 & 7 & 100 \\
\hline 9. & $\begin{array}{l}\text { Ibu kejang bukan merupakan tanda-tanda bahaya } \\
\text { persalinan }\end{array}$ & 7 & 100 & 7 & 100 \\
\hline 10. & $\begin{array}{l}\text { Keluar cairan berbau merupakan salah satu tanda bahaya } \\
\text { ibu nifas }\end{array}$ & 7 & 100 & 100 & 100 \\
\hline
\end{tabular}

Berdasarkan tabel 3 didapatkan hasil :

1. Pada pre test dari 7 responden terdapat 5 responden (71\%) dapat menjawab pertanyaan no. 2 dan pada post test meningkat menjadi 7 responden (100\%)

2. Pada pre test dari 7 responden terdapat 6 responden (85\%) dapat menjawab pertanyaan no. 5 dan pada post test meningkat menjadi 7 responden (100\%)

3. Pada pre test dari 10 responden terdapat 5 responden (71\%) dapat menjawab pertanyaan no. 6 dan pada post test meningkat menjadi 7 responden (100\%)

4. Pada pre test dari 10 responden terdapat 4 responden (57\%) dapat menjawab pertanyaan no.7 dan pada post test meningkat menjadi 6 responden (85\%)

Pada pertemuan ketiga kelas ibu hamil dengan materi Pencegahan Penyakit, Komplikasi Kehamilan Persalinan dan Nifas Agar Ibu Bayi Sehat dihadiri oleh 7 peserta. Seluruh 
peserta ibu hamil mengisi pre test dan post dengan menggunakan google form yang terdiri dari 10 pertanyaan. Dari 10 pertanyaan tersebut 6 pertanyaan dapat dijawab dengan benar oleh seluruh responden pada saat pre test dan post test. Sementara 4 pertanyaan lainnya dapat dijawab benar oleh antara 4-6 (57\%-85\%) responden pada saat pre test dan meningkat menjadi $85 \%-100 \%$ pada saat post test. Pada pertemuan ketiga kelas ibu hamil dapat disimpulkan bahwa terjadi peningkatan pengetahuan pada peserta.

\section{Tabel 4}

\section{Distribusi Frekuensi Hasil Pre Test dan Post Test Pelaksanaan Kelas Ibu Hamil Pertemuan IV Di UPK Abdul Radjak Pondok Gede}

\begin{tabular}{|c|c|c|c|c|c|}
\hline \multirow[t]{2}{*}{ No. } & \multirow[t]{2}{*}{ Pertanyaan } & \multicolumn{2}{|c|}{ Pre test } & \multicolumn{2}{|c|}{ Post Test } \\
\hline & & $\begin{array}{c}\text { Jumla } \\
\text { h }\end{array}$ & $\%$ & $\begin{array}{c}\text { Juml } \\
\text { ah }\end{array}$ & $\%$ \\
\hline 1. & $\begin{array}{l}\text { Bayi lahir segera menangis merupakan salah satu tanda } \\
\text { bayi lahir sehat }\end{array}$ & 7 & 100 & 7 & 100 \\
\hline 2. & $\begin{array}{l}\text { Pemberian ASI eksklusif pada bayi diberikan sampai umur } \\
4 \text { bulan }\end{array}$ & 7 & 100 & 7 & 100 \\
\hline 3. & $\begin{array}{l}\text { Pemberian makanan bergizi pada bayi dapat mencegah } \\
\text { perdarahan pada bayi karena kekurangan vitamin K1 }\end{array}$ & 4 & 57 & 7 & 100 \\
\hline 4. & $\begin{array}{l}\text { Bayi tidak mau menyusu merupakan salah satu tanda } \\
\text { bahaya bayi baru lahir }\end{array}$ & 7 & 100 & 7 & 100 \\
\hline 5. & $\begin{array}{l}\text { Salah satu posisi menyusu yang benar adalah wajah bayi } \\
\text { menghadap payudara ibu }\end{array}$ & 3 & 43 & 6 & 86 \\
\hline 6. & $\begin{array}{l}\text { Imunisasi BCG dapat menjaga kekebalan tubuh bayi } \\
\text { sehingga tidak mudah kena penyakit polio }\end{array}$ & 7 & 100 & 7 & 100 \\
\hline 7. & $\begin{array}{l}\text { Cuci tangan dengan sabun sebelum dan sesudah merawat } \\
\text { bayi dapat menjaga bayi agar tetap sehat }\end{array}$ & 7 & 100 & 7 & 100 \\
\hline 8. & $\begin{array}{l}\text { Menghindarkan bayi dari asap rokok maupun asap dapur } \\
\text { dapat menjaga bayi tetap sehat }\end{array}$ & 7 & 100 & 7 & 100 \\
\hline
\end{tabular}




\begin{tabular}{|r|l|c|c|c|c|}
\hline 9. & $\begin{array}{l}\text { Ibu hamil tidak boleh minum es selama kehamilan karena } \\
\text { dapat menyebabkan bayi besar }\end{array}$ & 6 & 85 & 7 & 100 \\
\hline 10. & $\begin{array}{l}\text { Akte kelahiran dapat dipergunakan untuk persyaratan } \\
\text { masuk sekolah }\end{array}$ & 7 & 100 & 7 & 100 \\
\hline
\end{tabular}

Berdasarkan tabel 3 didapatkan hasil :

1. Pada pre test dari 7 responden terdapat 4 responden (57\%) dapat menjawab pertanyaan no. 3 dan pada post test meningkat menjadi 7 responden (100\%)

2. Pada pre test dari 7 responden terdapat 3 responden (43\%) dapat menjawab pertanyaan no. 5 dan pada post test meningkat menjadi 6 responden (86\%)

3. Pada pre test dari 7 responden terdapat 6 responden (85\%) dapat menjawab pertanyaan no. 9 dan pada post test meningkat menjadi 7 responden (100\%) Pada pertemuan terakhir kelas ibu hamil dengan materi Pencegahan Penyakit Komplikasi Kehamilan Persalinan dan Nifas Agar Ibu Bayi Sehat dihadiri oleh 7 peserta. Seluruh peserta ibu hamil mengisi pre test dan post test dengan menggunakan google form yang terdiri dari 10 pertanyaan. Dari 10 pertanyaan tersebut 7 pertanyaan dapat dijawab dengan benar oleh seluruh responden pada saat pre test dan post test. Sementara 3 pertanyaan lainnya dapat dijawab benar antara 3-6 (43\%-85\%) pada pre test dan meningkat menjadi $86 \%-100 \%$ pada saat post test. Pada pertemuan terakhir kelas ibu hamil dapat disimpulkan bahwa terjadi peningkatan pengetahuan pada peserta.

\subsection{Pembentukan Kelas Ibu Hamil}

Setelah dilakukan pendampingan selama 4 kali pertemuan Kelas Ibu Hamil secara virtual dengan zoom meeting, maka Kelas Ibu Hamil di UPK Abdul Radjak sudah terbentuk pada tanggal Kamis, 3 November 2020 dengan struktur organisasi sebagai berikut: 


\section{STRUKTUR ORGANISASI KELAS IBU HAMIL}

UPK ABDUL RADJAK PONDOK GEDE

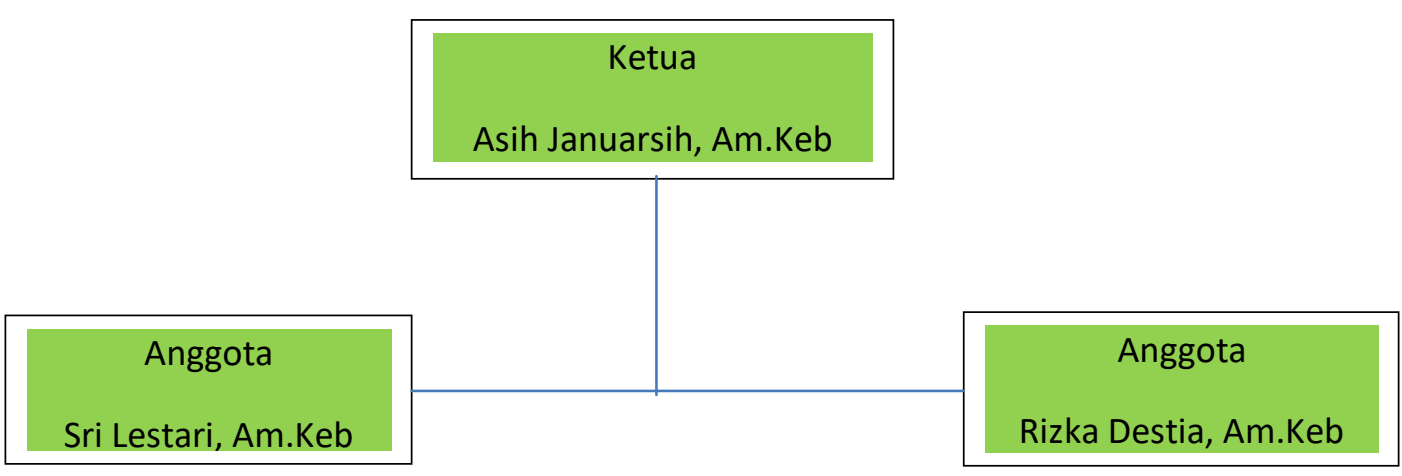

Mengetahui

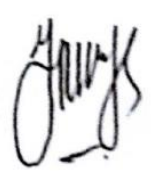

Munawaroh, SKM., MKM

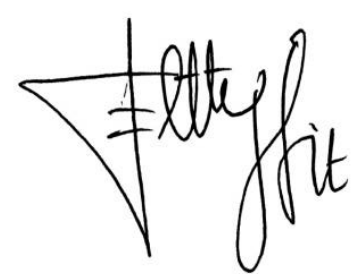

dr. Tety Sri Sitorus

Dengan terbentuknya struktur organisasi Kelas Ibu Hamil di UPK Abdul Radjak Pondok Gede, maka kelas ibu hamil sudah siap dalam memberikan pelayanan terhadap ibu hamil di wilayah kerja di UPK Abdul Radjak Pondok Gede. Namun demikian upaya-upaya promosi masih tetap harus dilakukan agar ibu hamil mau mengikuti kelas ibu hamil .

\section{SIMPULAN}

Terlaksananya kegiatan kelas Ibu Hamil di UPK Abdul Radjak Pondok Gede sebanyak 4 kali pertemuan secara virtual dengan Zoom Meeting pada Oktober 2020 yang dihadiri oleh ibu hamil, bidan UPK Abdul Radjak Pondok Gede dan pendamping.

Pada pelaksanaan Kelas Ibu Hamil telah terjadi peningkatan pengetahuan pada peserta kelas Ibu hamil yang di ukur melalui pre test dan post test.

Terbentuknya Kelas Ibu Hamil di UPK Abdul Radjak Pondok Gede pada Kamis, 3 November 2020. 


\section{DAFTAR PUSTAKA}

GUGUS TUGAS PERCEPATAN PENANGANAN COVID-19. Protokol Petunjuk Praktis Layanan Kesehatan Ibu dan Bayi Baru Lahir Selama Pandemi COVID-19. Protok Gugus Tugas Percepatan Penanganan Covid-19 Ri [Internet]. 2020;4(April):1-11. Available from: https://covid19.go.id/p/protokol/protokol-b-4-petunjuk-praktis-layanan-kesehatanibu-dan-bbl-pada-masa-pandemi-covid-19

Kemenkes RI. Pedoman Pelaksanaan Kelas Ibu Hamil Kemenkes RI 2009-2011. Kementrian Kesehatan RI. 2014. p. 1-26.

Kementrian Kesehatan RI. Laporan Riskesdas 2018. Lap Nas RIskesdas 2018 [Internet]. 2018;53(9):181-222. Available from:

http://www.yankes.kemkes.go.id/assets/downloads/PMK No. 57 Tahun 2013 tentang PTRM.pdf 